\title{
Adipose-Derived Stem Cell Features and MCF-7
}

\author{
Giuseppe Garroni ${ }^{1,+} \mathbb{D}^{D}$, Francesca Balzano ${ }^{1,+} \mathbb{D}^{D}$, Sara Cruciani ${ }^{1} \mathbb{D}$, Renzo Pala ${ }^{1}$, Donatella Coradduzza ${ }^{1} \mathbb{D}_{\text {, }}$ \\ Emanuela Azara ${ }^{2}$, Emanuela Bellu ${ }^{1}$, Maria Laura Cossu ${ }^{3}$ (D) Giorgio C. Ginesu ${ }^{3}$, Ciriaco Carru ${ }^{1}$ (D), \\ Carlo Ventura ${ }^{4}$ (D) and Margherita Maioli ${ }^{1,5, *(D)}$
}

1 Department of Biomedical Sciences, University of Sassari, Viale San Pietro 43/B, 07100 Sassari, Italy; giugarroni21@gmail.com (G.G.); mariafrancesca22@virgilio.it (F.B.); sara.cruciani@outlook.com (S.C.); renzopala6@gmail.com (R.P.); donatella.coradduzza@libero.it (D.C.); ema.bellu@hotmail.it (E.B.); carru@uniss.it (C.C.)

2 Institute of Biomolecular Chemistry, National Research Council, 07100 Sassari, Italy; emanuelagigliola.azara@cnr.it

3 Department of Medical, Surgical and Experimental Sciences, General Surgery Unit 2 "Clinica Chirurgica", University of Sassari, Viale San Pietro 8, 07100 Sassari, Italy; mlcossu@uniss.it (M.L.C.); ginesugc@uniss.it (G.C.G.)

4 Laboratory of Molecular Biology and Stem Cell Engineering, National Institute of Biostructures and Biosystems-Eldor Lab, Innovation Accelerator, Consiglio Nazionale Delle Ricerche, 40129 Bologna, Italy; ventura.vid@gmail.com

5 Center for Developmental Biology and Reprogramming (CEDEBIOR), Department of Biomedical Sciences, University of Sassari, Viale San Pietro 43/B, 07100 Sassari, Italy

* Correspondence: mmaioli@uniss.it; Tel.: +39-079-228-277

+ These authors contributed equally to this work.

Citation: Garroni, G.; Balzano, F.; Cruciani, S.; Pala, R.; Coradduzza, D.; Azara, E.; Bellu, E.; Cossu, M.L.; Ginesu, G.C.; Carru, C.; et al. Adipose-Derived Stem Cell Features and MCF-7. Cells 2021, 10, 1754. https://doi.org/10.3390/cells10071754

Academic Editor: Giorgio Malpeli

Received: 8 June 2021

Accepted: 9 July 2021

Published: 11 July 2021

Publisher's Note: MDPI stays neutral with regard to jurisdictional claims in published maps and institutional affiliations.

\section{Copyright: (c) 2021 by the authors.} Licensee MDPI, Basel, Switzerland. This article is an open access article distributed under the terms and conditions of the Creative Commons Attribution (CC BY) license (https:// creativecommons.org/licenses/by/ $4.0 /)$.

\begin{abstract}
Human adipose tissue-derived stem cells (hADSCs) are highly suitable for regeneration therapies being easily collected and propagated in vitro. The effects of different external factors and culturing conditions are able to affect hADSC proliferation, senescence, differentiation, and migration, even at the molecular level. In the present paper, we exposed hADSCs to an exhausted medium from the breast cancer cell line (MCF-7) to evaluate whether the soluble factors released by these cells may be able to induce changes in stem cell behavior. In particular, we investigated the expression of stemness-related genes (OCT4; Sox 2; Nanog), the cell-cycle regulators p21 (WAF1/CIP1) p53, epigenetic markers (DNMT1 and Sirt1), and autophagy-related proteins. From our results, we can infer that the exhausted medium from MCF-7 is able to influence the hADSCs behavior increasing the expression of stemness-related genes, cell proliferation, and autophagy. Polyamines detectable in MCF-7 exhausted medium could be related to the higher proliferation capability observed in hADSCs, suggesting direct crosstalk between these molecules and the observed changes in stem cell potency.
\end{abstract}

Keywords: adipose-derived stem cells; cellular mechanisms; epigenetics; cell proliferation; stemness genes; autophagy

\section{Introduction}

Stem cells have been largely explored in the branch of regenerative medicine, being able to replace damaged elements for their ability to undergo a differentiation process upon request [1]. They are a suitable tool for regeneration therapies due to their simple isolation procedure and high proliferative capability in culture [2], low immunogenicity and immunosuppressive properties, being more stable in long-term culture, with lower senescence and greater proliferation capabilities as compared to other kinds of stem cells [3,4].

Human adipose-derived stem cells (hADSCs) are able to differentiate into different cell lineages upon stimulation using a conditioned medium, as demonstrated in several studies [5-7]. 
In particular, small molecules or physical energies from the microenvironment can act by modulating and modifying different pathways, such as stem cell self-renewal, inducing differentiation, and cell reprogramming [8-10].

This kind of behavior depends on stemness genes, including the octamer-binding transcription factor 4 (OCT4), SOX2, and Nanog [11], involved and expressed in undifferentiated stem cells [12], being related not only to the maintenance of an undifferentiated state but also to cell proliferation [13].

OCT4 is a key marker of stemness, implicated in lineage specification and reprogramming of somatic cells in vitro, together with SOX2 [14,15].

NANOG is a stem cell transcription factor playing an important role in the regulation of human development; it is involved in cell fate determination, proliferation, and apoptosis [16,17].

OCT4, Nanog, and SOX2 dysregulation has been related to different kinds of tumors, being upregulated in breast, colorectal, and liver cancers [18-20].

Together with stemness modulation, epigenetic modifications play an important role in stemness maintenance, cell differentiation, and the development of neoplasia [21-23]. Sirtuin 1 (Sirt1) and Dnmt1 DNA (cytosine-5)-methyltransferase 1 (DNMT1) affect both cell proliferation and differentiation, being associated with several cancer processes, and regulating cell cycle-associated genes [24-27].

These observations highlight the relevance of the stem cell microenvironment in conditioning fate decisions and adaptation processes. hADSCs have been widely used in regenerative and aesthetic/plastic reconstruction medicine being transplanted with different modalities in recipient injured tissues, whose derangement was not depending upon pre-existing malignancies, but it was rather resulting from hypoxic/ischemic, traumatic, and inflammatory conditions.

Nevertheless, autologous hADSCs and adipose tissue derivatives are increasingly used after mastectomy for breast cancer removal [28], with the aim of developing new approaches to breast reconstruction and tissue augmentation with natural appearance and texture. Under these clinical and surgical circumstances, it is conceivable that the recipient tissue is still retaining, at least in part, the molecular cues of a tumor microenvironment, as it has been consistently shown in the case of cancer cell dormancy and reentry even after thorough surgery and chemo-/radio-therapy [29]. The tumor microenvironment (TME) is a complex system comprising different cell populations as adipocytes, fibroblasts, and different stem and progenitor cells [30,31], interacting with soluble secreted factors in tumor progression [32]. The same microenvironment also encompasses different organic compounds capable of modulating cellular decisions at different interconnected levels. Among these molecules, polyamines are able to influence cell behavior in different situations. Their interaction with nucleic acids, proteins, and negatively charged phospholipids results in a change in their structure and conformation [33,34]. Thus, polyamines regulate cell growth and proliferation, as well as stem cell differentiation [35]. They are also involved in necrosis, apoptosis, and autophagy. Consonant with their pleiotropic features, polyamine levels are often dysregulated in cellular aging, cancer, and other hyperproliferative diseases [36].

We have previously highlighted the relevance of the tumor microenvironment in stem cell dynamics, showing that an exhausted medium from human hepatocarcinoma cell line HepG2 was able to remarkably affect both the stemness and the proliferative state in Wharton jelly mesenchymal stem cells [37].

In the present study, we investigated whether an exhausted medium from the breast cancer cell line MCF-7 may alter a number of essential features in hADSCs, including stemness, proliferation, and autophagy. We also assessed whether the same exhausted medium may prime an hADSC switch toward a malignant phenotype.

In particular, we analyzed the expression of the stemness-related genes, NANOG, OCT4, SOX2, the epigenetic modulator genes DNMT1, SIRT1, and the expression of p53 and its ability to modulate cell-cycle arrest/progression by p21 (WAF1/CIP1), and apoptosis induction by BAX. Here, we also decided to assess the polyamine content in 
MCF-7-exhausted medium and in the course of autophagy, a fundamental cell survival process through which cells are able to adapt to metabolic stresses. In particular, autophagy appears to contribute to the survival of cancer (stem)cells, which are forced to a high requirement for nutrients and oxygen to ensure their proliferation [38]. Moreover, cell fate and stem cell quiescence, activation, differentiation, self-renewal, and proliferation are influenced by autophagy [39].

\section{Materials and Methods}

\subsection{Adipose-Derived Stem Cell Isolation and Culturing}

Human Adipose-derived Stem cells (hADSCs) were obtained from subcutaneous adipose tissue of human adult patients during surgery procedures $(n=6$, age $=45 \pm 15$ years, BMI: $22 \pm 3 \mathrm{~kg} / \mathrm{m}^{2}$ ), as previously described in Basoli V. et al. (2016) [5].

The study was approved by the Ethics Committee Review Boards for Human Studies in Sassari (n_ETIC 240I/CE 26 July 2016, Ethical committee, ASL Sassari). All patients signed written informed consent. Before isolation, the fat tissue was washed two times with sterile Dulbecco's phosphate-buffered saline (DPBS) (Euroclone, Milano, Italy) with $200 \mathrm{U} / \mathrm{mL}$ penicillin- $0.1 \mathrm{mg} / \mathrm{mL}$ streptomycin (Euroclone, Milano, Italy). Tissue biopsies were mechanically reduced to small fragments by sterile scalpels and enzymatically digested in a solution of Hanks' salts, $\mathrm{CaCl}_{2}$, and $0.1 \%$ Type I Collagenase (Gibco Life Technologies, Grand Island, NY, USA) at $37^{\circ} \mathrm{C}$ for $1 \mathrm{~h}$ to separate hADSCs from the stromal vascular fraction (SVF), and from mature adipocytes, that were removed. After the incubation time, the samples were filtered in a $70 \mu \mathrm{m}$ cell strainer (Euroclone, Milano, Italy) and centrifuged $10 \mathrm{~min}$ at $600 \times g$ to separate the different cell fractions. The resulting pellets of SVF were resuspended into a hADSCs growth medium with basic Dulbecco's Modified Eagle's Medium (DMEM) (Life Technologies Grand Island, NY, USA) supplemented with 20\% fetal bovine serum (FBS) (Life Technologies, Grand Island, NY, USA), 200 mM L-glutamine (Euroclone, Italy), and $200 \mathrm{U} / \mathrm{mL}$ penicillin- $0.1 \mathrm{mg} / \mathrm{mL}$ streptomycin (Euroclone, Milano, Italy) and transferred in an incubator at $37{ }^{\circ} \mathrm{C}$ and $5 \% \mathrm{CO}_{2}$. The culture medium was replaced every 3 days. hADSCs at confluence were detached from the flask using $0.25 \%$ EDTA trypsin (Euroclone, Milan, Italy), counted, and then immunomagnetically separated from the SVF and characterized by flow cytometry [5]. Flow cytometry analysis was exploited to assess the percentage of mesenchymal markers and the homogeneity of the isolated population. After fixation, cells were permeabilized and incubated with primary antibodies directed against CD73, CD90 (BD Biosciences, San Jose, CA, USA), CD105 (Santa Cruz Biotechnology, Heidelberg, Germany), CD45, and CD31 (Sigma-Aldrich, Munich, Germany) (all at $1 \mu \mathrm{g} / 106$ cells) for $1 \mathrm{~h}$ at $4^{\circ} \mathrm{C}$, and with $1 \mu \mathrm{g}$ of fluorescein isothiocyanate (FITC)-conjugated secondary antibody for $1 \mathrm{~h}$ at $4{ }^{\circ} \mathrm{C}$ in the dark. After washing, cells were analyzed on a flow cytometer (CytoFlex, Backman Coulter, Milan, Italy) as previously described in Basoli V. et al. (2016) [5].

\subsection{MCF-7 Cell Culturing}

MCF-7 cell line (ATCC, Manassas, VA, USA) were maintained in Dulbecco's Modified Eagle's Medium (DMEM) (Life Technologies Grand Island, NY, USA) supplemented with 10\% fetal bovine serum (FBS) (Life Technologies, Grand Island, NY, USA), 200 mM L-glutamine (Euroclone, Italy), and $200 \mathrm{U} / \mathrm{mL}$ penicillin- $0.1 \mathrm{mg} / \mathrm{mL}$ streptomycin (Euroclone, Milano, Italy). Cells were grown in $75 \mathrm{~cm}^{2}$ tissue culture flasks in the culture incubator at $37{ }^{\circ} \mathrm{C}$ with $5 \% \mathrm{CO}_{2}$ and saturated humidity. The exhausted medium was collected, after 4,7 , and 10 days in culture, when the cells reached $80 \%-90 \%$ confluence, then it was centrifuged for $5 \mathrm{~min}$ at $600 \times g$ and filtered in a $0.22-\mu \mathrm{m}$ cell strainer (Primo ${ }^{\circledR}$ Syringe Filters Euroclone, Milano, Italy). From here on, the exhausted medium obtained from MCF-7 (MCF-7-EM) cultured for 4, 7, or 10 days will be referred to as 4d-MCF-7-EM, 7d-MCF-7-EM, and 10d-MCF-7-EM, respectively. 


\subsection{ADSC Treatment}

hADSCs were seeded on 6-well plates and then exposed for $72 \mathrm{~h}$ to $1.5 \mathrm{~mL}$ of $4 \mathrm{~d}$ MCF-7-EM, 7d-MCF-7-EM, or 10d-MCF-7-EM. A group of cells was exposed to $1.5 \mathrm{~mL}$ of hADSCs basic growth medium, representing the cells used as untreated controls in the study, indicated as Ctrl. The 6-well cell culture plates were placed in a $37^{\circ} \mathrm{C}$ incubator with $5 \% \mathrm{CO}_{2}$ and saturated humidity. After the 3 days of treatment, the medium was removed and replaced by $1.5 \mathrm{~mL}$ of fresh hADSCs basic growth medium for an additional 4 days before proceeding with the following analysis, for a total incubation time of 7 days (Figure 1).

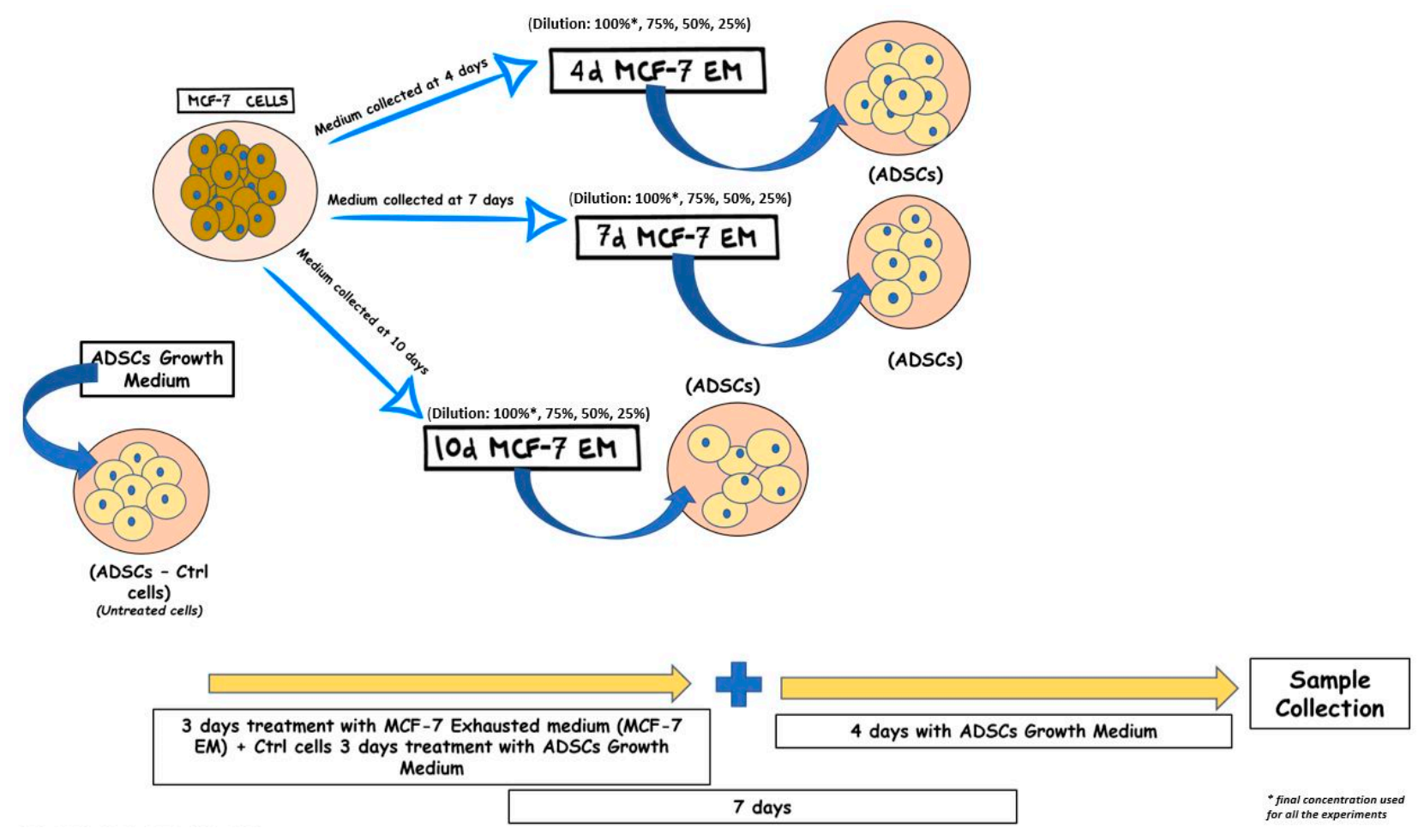

Figure 1. MCF-7 cell culturing and hADSC treatment.

\subsection{BrdU Cell Proliferation Assay}

For the BrdU (5-Bromo-2-Deoxyuridine) proliferation assay, cells were seeded on 24-well plates and treated with MCF-7-EM at different time points. A group of cells was exposed to hADSCs basic growth medium, representing the cells used as untreated controls in the study, indicated as Ctrl. The proliferation assay BrdU Cell Proliferation Assay Kit (Cell Signaling Technology, Danvers, MA, USA) was performed. According to the manufacturer's protocol, cells were fixed and incubated with 1X detection antibody solution and then with 1X HRP-conjugated secondary antibody solution. At the end of the incubation time, absorbance was monitored by spectrophotometric reading at $450 \mathrm{~nm}$ (Akribis Scientific, Common Farm, Frog Ln, Knutsford WA16 0JG, Great Britain).

\subsection{MTT Viability Assay}

hADSCs were exposed to different concentrations $(100 \%, 75 \%, 50 \%, 25 \%)$ of the MCF-7exhausted medium collected after 4, 7, and 10 days to evaluate its possible cytotoxic effect.

The colorimetric test of MTT 3-(4,5-Dimethylthiazol-2-yl)-2,5-Diphenyltetrazolium Bromide) (Sigma-Aldrich, Saint Louis, MO, USA) was used. Vital cells were able to reduce this compound, producing formazan that can be quantified by spectrophotometer at $570 \mathrm{~nm}$. The hADSCs were seeded at a concentration of 5000 cells/well in 96-well plates. Cells used as untreated control were grown in the only basic growing medium. At the end 
of the incubation period, the medium containing the extracts was removed, and $100 \mu \mathrm{L}$ of MTT at the final concentration of $0.65 \mathrm{mg} / \mathrm{mL}$ was added to each well and incubated for $2 \mathrm{~h}$. After incubation, the formazan was dissolved in DMSO, and the absorbance was detected by spectrophotometric reading at $570 \mathrm{~nm}$ (Akribis Scientific, Common Farm, Frog Ln, Knutsford WA16 0JG, Great Britain). The viability of cultured cells in the presence of exhausted medium was calculated as \% cell viability compared to the untreated control:

$($ OD570 treated cells $) \times 100 /($ OD570 control $)$ considered as 100)

\subsection{RNA Extraction and Real-Time Quantitative Polymerase Chain}

Total mRNA was isolated from hADSCs cultured in the above-described conditions using PureLinkTM RNA Mini kit (Ambion, Life Technologies), according to the manufacturer's protocol. Quantity and purity of RNA were measured using Nanodrop (Thermo Scientific, Waltham, MA, USA). Quantitative polymerase chain reaction (RT- qPCR) was performed using a CFX Thermal Cycler (Bio-Rad) in triplicate under standard RT- qPCR conditions $\left(55^{\circ} \mathrm{C}\right.$ for $10 \mathrm{~min}, 95^{\circ} \mathrm{C}$ for $1 \mathrm{~min}$, and then cycled at $95^{\circ} \mathrm{C}$ for $10 \mathrm{~s}, 60^{\circ} \mathrm{C}$ for $30 \mathrm{~s}$, for 40-45 cycles), using Luna ${ }^{\circledR}$ Universal One-Step RT-qPCR Kit (New England Biolabs). Luna Universal One-Step Reaction Mix (2X) $10 \mu \mathrm{L}$, Luna WarmStart ${ }^{\circledR}$ RT Enzyme Mix (20X) $1 \mu \mathrm{L}, 0.4 \mu \mathrm{M}(0,8 \mu \mathrm{L})$ of each primer, and $2.5 \mu \mathrm{L}(2.5 \mathrm{ng})$ of the total RNA template were mixed in $20 \mu \mathrm{L}$ volumes and added to each reaction. Relative expression was determined using the "delta-CT method" with Glyceraldehyde-3-Phosphate Dehydrogenase (GAPDH) as a reference gene. The mRNA levels of treated cells were expressed as fold of change $\left(2^{-\Delta \Delta \mathrm{Ct}}\right)$ of mRNA levels observed in control untreated cells. The RT-qPCR analysis was performed for the following set of genes: NANOG, Oct-4, SOX2, p53, p21 (WAF1/CIP1), Sirt1, and DNMT1. All primers used (Thermo Scientific, Waltham, MA, USA) are described in Table 1.

Table 1. Primer sequences.

\begin{tabular}{ccc}
\hline Primer Name & Forward & Reverse \\
\hline OCT4 & GAGGAGTCCCAGGCAATCAA & CATCGGCCTGTGTATATCCC \\
SOX2 & CCGTTCATGTAGGTCTCGGAGCTG & CAACGGCAGCTACAGCTAGATGC \\
Nanog & CATGAGTGTGGATCCAGCT & CCTGAATAAGCAGATCCAT \\
SIRT1 & CATTTCCATGGCGCTGAGG & TGCTGGTGGAACAATTCCTGT \\
DNMT1 & CGTCCGAGCGTCACACA & GAGCCTTTGCCATTCTTCGC \\
p53 & CAAGCAATGGATGATTTGATGCT & TGGGTCTTCAGTGAACCATTGT \\
p21 (WAF1/CIP) & CAAAGGCCCGCTCTACATCTT & AGGAACCTCCATTCACCCGA \\
BAX & TGCTTCAGGGTTTCATCCAG & GGCGGCAATCATCCTCTG \\
GAPDH & GAGTCAACGGATTTGGTCGT & GACAAGCTTCCCGTTCTCAG \\
\hline
\end{tabular}

\subsection{Autophagosome Detection Assays}

To investigate the accumulation of autophagosomes in hADSCs cultured under the above-described conditions, Autophagosome Marker Antibody Sampler Kit (Cell Signaling Technology, Danvers, MA, USA) was used. After 7 days in culture, hADSCs were lysed by adding $1 X$ SDS sample buffer according to the manufacturer's protocol. Samples were then denatured at $95-100{ }^{\circ} \mathrm{C}$ for $5 \mathrm{~min}$ and loaded onto an SDS-PAGE gel. After transferring to a nitrocellulose membrane, samples were incubated in blocking buffer for $1 \mathrm{~h}$ at RT (room temperature) and then in primary antibody $\mathrm{ON}$ (Overnight) at $4{ }^{\circ} \mathrm{C}$. At the end of incubation, the membrane was washed three times in TBS and incubated with an HRP-conjugated secondary antibody for $1 \mathrm{~h}$ at RT. Protein expression was assessed by SuperSignal Chemiluminescent HRP Substrates (Thermo Fisher Scientific, Grand Island, NY, USA). 


\subsection{Polyamine Analysis}

\subsubsection{Chemicals}

The reference standards of putrescine, cadaverine hydrochloride, spermidine hydrochloride, spermine, agmatine sulfate salt, $\mathrm{N}$-acetyl-putrescine hydrochloride, $\mathrm{N}$-acetylspermine trihydrochloride, $\mathrm{N}$-acetyl-spermidine dihydrochloride, L-ornithine hydrochloride, lysine, L-arginine, S-adenosyl-1-methionine, aminobutyric acid, deuterated histamine, heptafluorobutyric acid (HFBA), and methanol LC/MS grade were purchased from SigmaAldrich (St. Louis, MO, USA). Water for LCMS was purchased from Fisher Scientific (Fair Lawn, NJ, USA).

\subsubsection{LC-HRMS}

Liquid chromatography-tandem high-resolution mass spectrometry (LC-HRMS) analysis was performed using a UPLC Ultimate 3000 (Thermo Fisher-Dionex San Jose, CA, USA) system equipped with a HESI-II electrospray source to a Q-Exactive Orbitrap ${ }^{\text {TM }}$-based mass spectrometer (all from Thermo Scientific, San Jose, CA, USA). Chromatographic separation was performed on Phenomenex Gemini C18 $(100 \times 2 \mathrm{~mm}), 3 \mu \mathrm{m}$ particle size, the column was held at $37^{\circ} \mathrm{C}$. Peaks were obtained at a flow rate of $0.4 \mathrm{~mL} \mathrm{~min}{ }^{-1}$ with a sample injection volume of $5 \mu \mathrm{L}$.

Q-Orbitrap HRMS (Thermo Scientific, San Jose, CA) with HESI-II electrospray source was operated in positive mode. The Xcalibur ${ }^{\mathrm{TM}} 3.1 .66$ software (Thermo Scientific, Bremen, Germany) was used to control the instruments and to process the data [36].

\subsubsection{Sample Preparation}

Protein extraction and precipitation were performed as follows: $250 \mu \mathrm{L}$ of medium were transferred into an Eppendorf microtube and mixed with $150 \mu \mathrm{L}$ methanol (containing $0.05 \% \mathrm{HFBA}$ ) and $100 \mu \mathrm{L}$ water for $50 \mathrm{~s}$. After precipitation, samples were centrifuged for $9 \mathrm{~min}$ at $15,000 \mathrm{rpm}$, and the supernatant was evaporated to dryness at $37^{\circ} \mathrm{C}$ under a stream of nitrogen. The residue was reconstituted in $500 \mu \mathrm{L}$ of methanol/water (20:80 $v / v)$ solution and $50 \mu \mathrm{L}$ of IS (deuterated histamine). An aliquot of $5 \mu \mathrm{L}$ of the solution was injected into the HPLC-MS/MS system for analysis.

\subsection{Statistical Analysis}

Statistical analysis was performed using Statistical Package for the Social Sciences version 13 software (SPSS Inc., Chicago, IL, USA). The experiments were performed two times with three technical replicates for each treatment. For this study, KruskalWallis rank sum and Wilcoxon signed-rank test were used, assuming a $p$-value $<0.05$ as statistically significant.

\section{Results}

\subsection{Morphological Analysis of ADSCs Exposed to MCF7-Exhausted Medium}

Figure 2 shows the hADSC morphology evaluated by optical microscopy (Leica, Nussloch, Germany) after 7 days of culturing, according to the above-described conditions. We did not observe significant changes in the morphology of the cells exposed to 4d-MCF7-EM (4d), while hADSCs that had been exposed to 7d-MCF-7-EM (7d) or 10d-MCF-7-EM (10d) showed significant changes in their morphology, as compared to control untreated cells (Ctrl). 
Ctrl

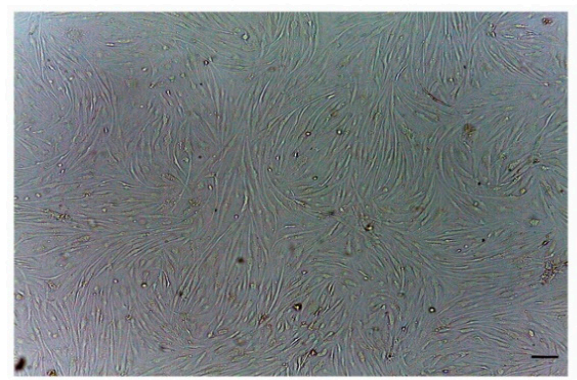

7d

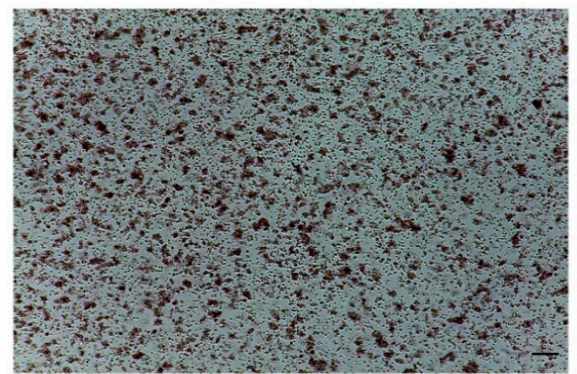

4d

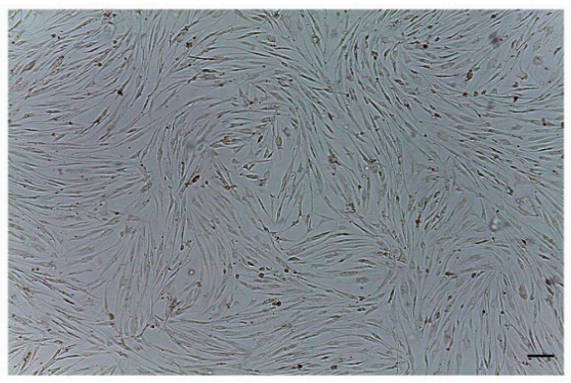

10d

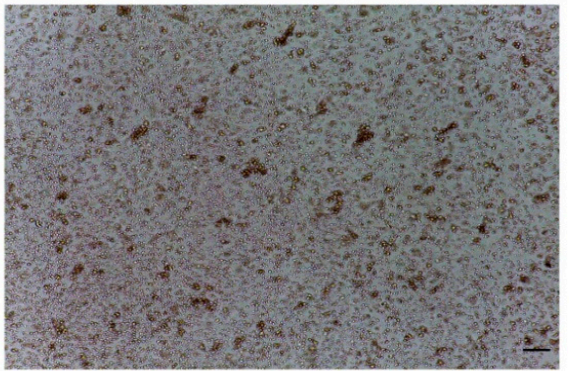

Figure 2. Optical microscope analysis of hADSC morphology after exposure to MCF-7-exhausted media. Figure 2 shows morphological changes in cell treated with 4d-MCF-7-EM (4d), or 7d-MCF-7EM (7d) or 10d-MCF-7-EM (10d), as compared to untreated control cells (Ctrl). Scale bar $=100 \mu \mathrm{m}$.

\section{2. hADSCs Exposed to Exhausted Medium Undergo Cell-Cycle Progression through G1/S Phase}

The BrdU assay showed that cell proliferation was increased in hADSCs exposed to 4d-MCF-7-EM (4d - red bars), 7d-MCF-7-EM (7d - green bars), or 10d-MCF-7-EM (10d - blue bars), as compared to control untreated cells (Ctrl - grey bars).

Cells treated with 10d-MCF-7-EM showed a higher proliferation rate when compared to cells cultured in all the other described conditions, but there is no significant difference compared to control cells (Figure 3).

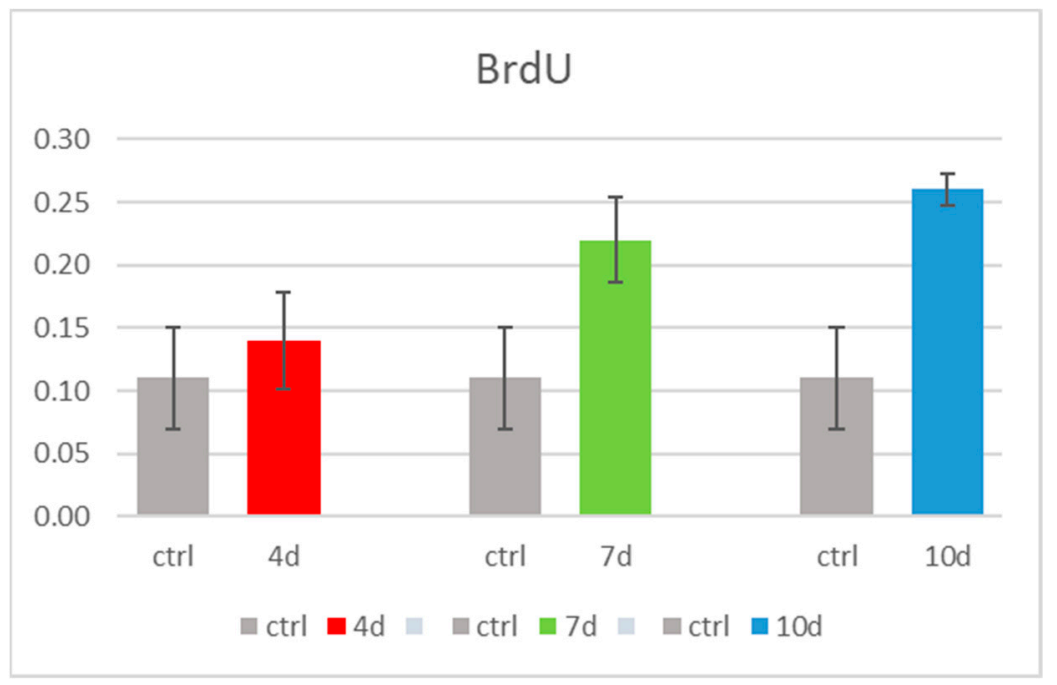

Figure 3. BrdU cell proliferation analysis in hADSCs cultured with 4d-MCF-7-EM (4d - red bars), or 7d-MCF-7-EM (7d - green bars) or 10d-MCF-7-EM (10d - blue bars), as compared to control untreated hADSCs (Ctrl - grey bars). 


\subsection{Exhausted Medium Does Not Affect Cell Viability}

We tested different concentrations of the MCF-7 exhausted medium; $100 \%$ indicates pure exhausted medium collected after 4,7 , and 10 days of culture; $75 \%$ indicates a dilution of $75 \%$ of pure exhausted medium collected after 4,7 , and 10 days and $25 \%$ growth medium; $50 \%$ indicates $50 \%$ pure exhausted medium collected after 4,7 , and 10 days, and $50 \%$ growth medium; $25 \%$ indicates $75 \%$ growth medium and $25 \%$ pure exhausted medium collected after 4,7 , and 10 days in hADSCs. The control groups were hADSCs cultured in the presence of the growing medium alone.

MTT assay shows that pure exhausted medium and dilutions did not reduce hADSC viability as compared to untreated control cells (Figure 4). Moreover, the pure media (100\%) was the only one able to guarantee a constant release of its components for each observed time point (Supplementary Material).

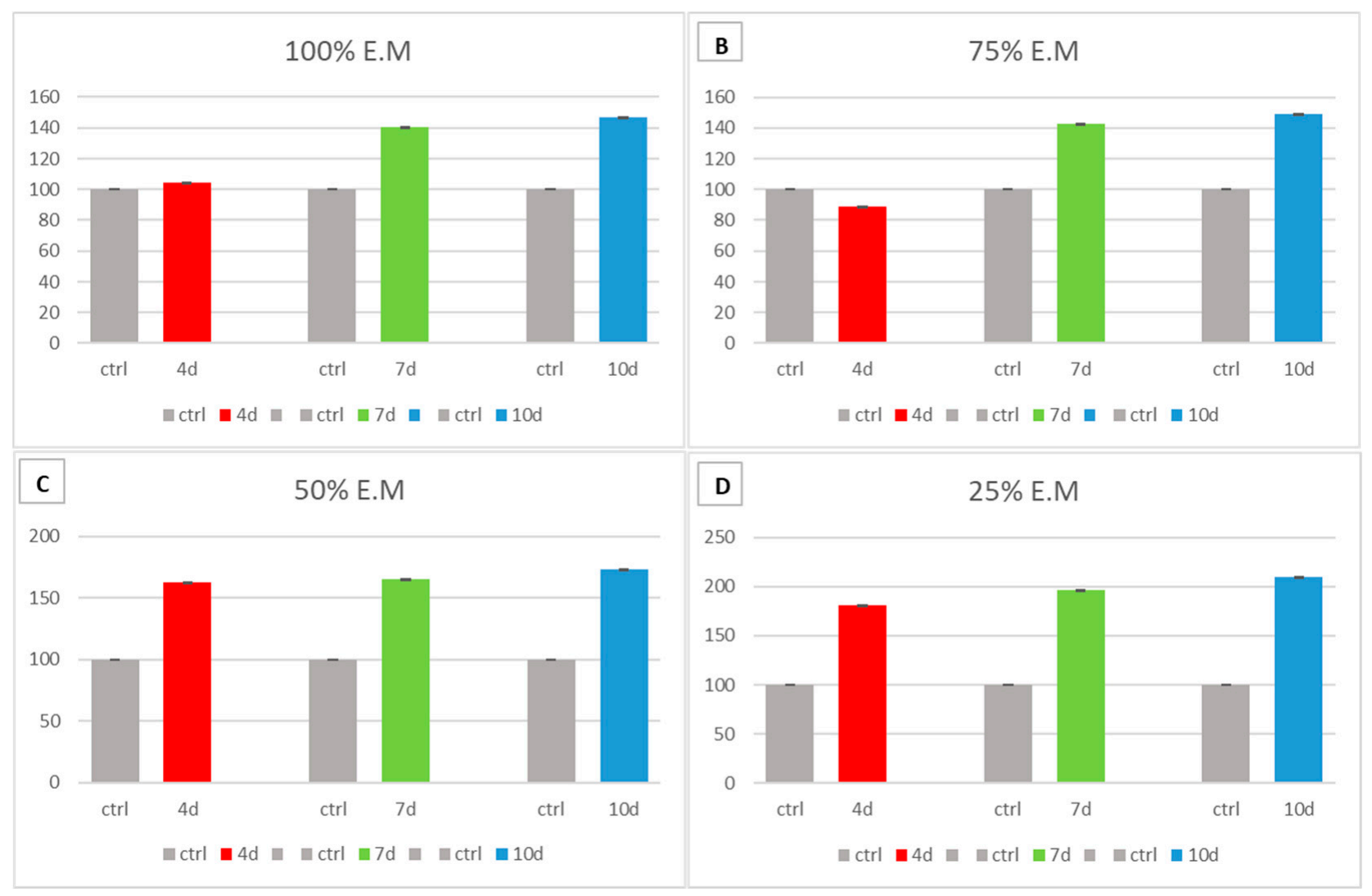

Figure 4. Figure 4 shows the MTT vitality assay. The cytotoxicity of the exhausted medium collected at 4 (red bars), 7 (green bars) and 10 (blue bars) days was evaluated in hADSCs in the presence of different concentrations MCF-7-Exhausted Medium (100\% MCF-7-Exhausted Medium (A), 75\% MCF-7 E.M (B), 50\% MCF-7 E.M (C), and 25\% MCF-7 E.M (D)). Cell viability was compared to untreated controls hADSCs cultured in the presence of the basic growing medium alone (grey bars) and expressed as absorbance at $570 \mathrm{~nm}$. The experiments were performed with three technical replicates for each treatment. Data are expressed as mean \pm SD referred to the control.

\subsection{Exposure of hADSCs to Exhausted MCF- 7 Medium Increases Stem Cell Potency}

Figure 5 shows the mRNA levels of stemness-related genes in hADSCs exposed to $4 \mathrm{~d}-$ MCF-7-EM (4d-red bars), 7d-MCF-7-EM (7d-green bars) or 10d-MCF-7-EM (10d-blue bars) in culture. The expression of all the tested stemness genes was significantly upregulated in cells cultured in the presence of the exhausted medium, as compared to control untreated cells (Ctrl - grey bars). 


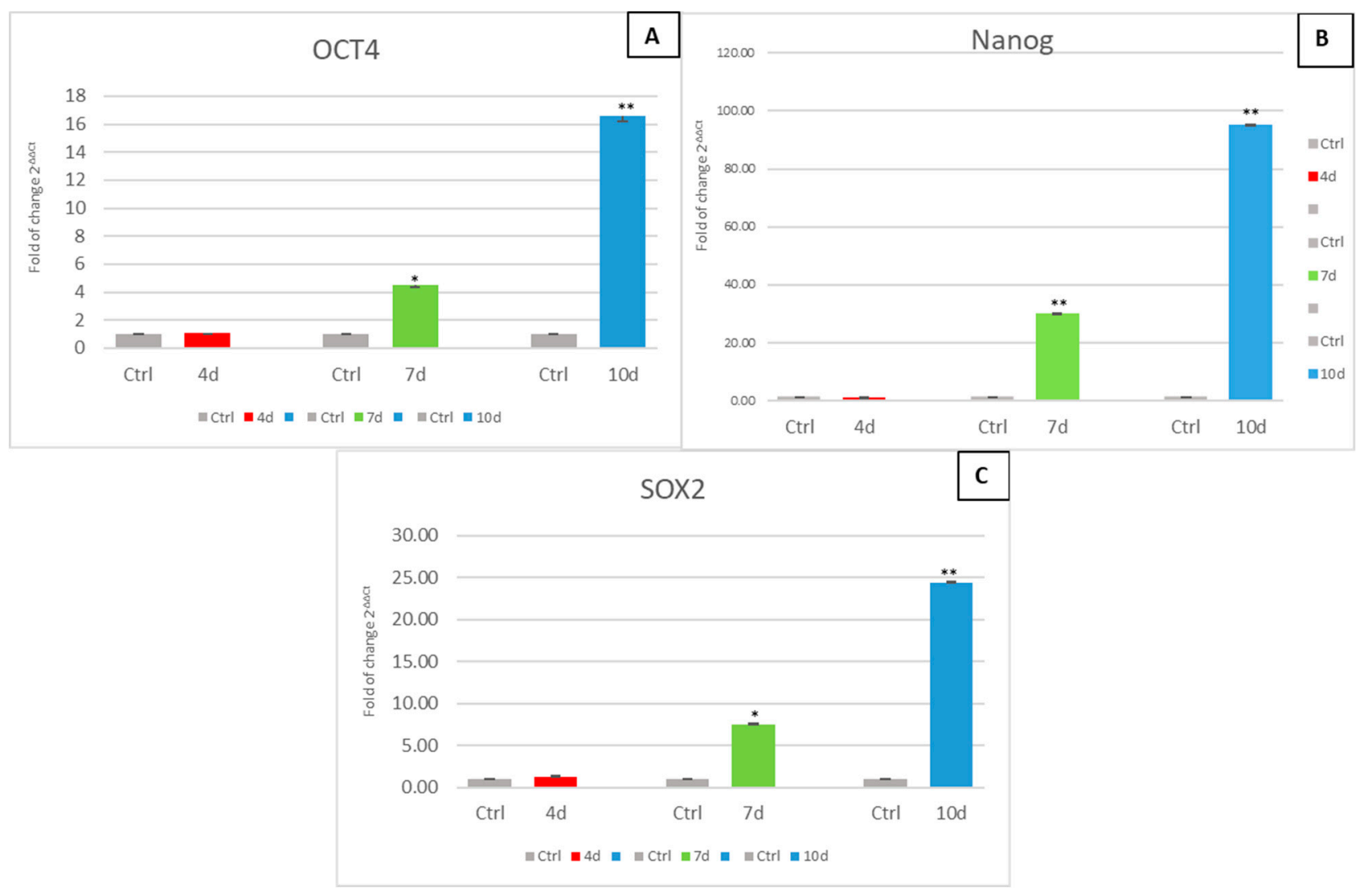

Figure 5. Expression of stemness genes. The expression of stemness-related genes OCT4 (Panel (A)), Nanog (Panel (B)), and SOX2 (Panel (C)) was evaluated in hADSCs cultured with 4d-MCF-7-EM (4d - red bars), 7d-MCF-7-EM (7d - green bars), or 10d-MCF-7-EM (10d - blue bars). The mRNA levels for each gene were normalized to Glyceraldehyde-3-PhosphateDehydrogenase (GAPDH) and expressed as fold of change $\left(2^{-\Delta \Delta C t}\right)$ of the mRNA levels observed in untreated control hADSCs (Ctrl - grey bars) defined as 1 (mean $\pm \mathrm{SD} ; n=6$ ). Data are expressed as mean \pm SD referred to the control $\left({ }^{*} p \leq 0.05\right),\left({ }^{* *} p \leq 0.01\right)$.

\subsection{Exhausted MCF- 7 Medium Influence on p53, p21 (WAF1/CIP1) and BAX}

Figure 6 shows the mRNA levels of cell cycle-related genes p53 and p21 (WAF1/CIP1) and pro-apoptosis gene BAX in hADSCs exposed to 4d-MCF-7-EM (4d-red bars), 7d-MCF7-EM (7d-green bars), or 10d-MCF-7-EM (10d-blue bars). In medium-treated cells, the expression of the tested genes was downregulated, as compared to untreated controls (Ctrl-grey bars). 


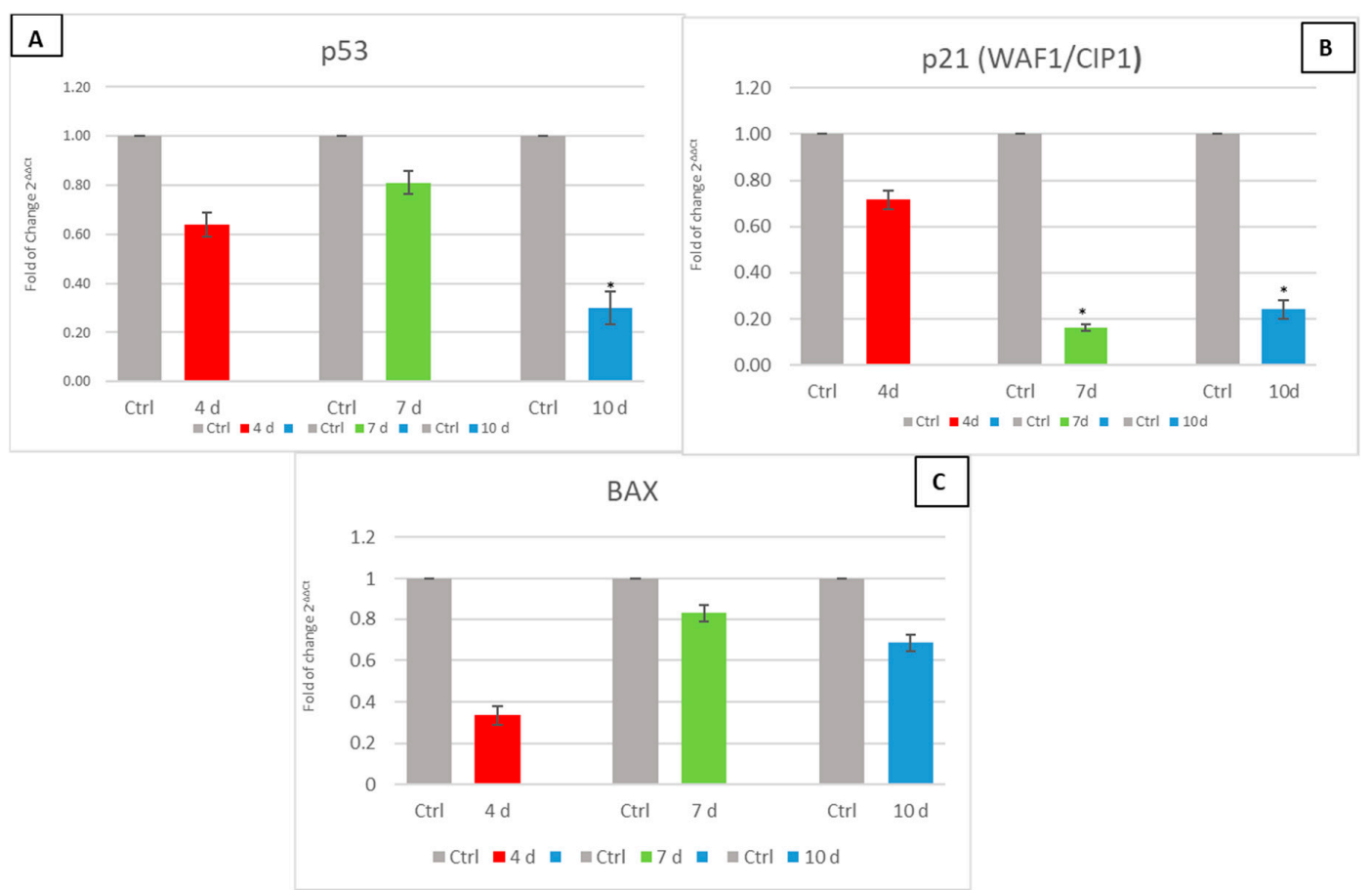

Figure 6. The expression of p53 (Panel (A)), p21 (WAF1/CIP1) (Panel (B)), and BAX (Panel (C)) was evaluated in human Adipose-derived stem cells (hADSCs) cultured with 4d-MCF-7-EM (4d - red bars), 7d-MCF-7-EM (7d - green bars), or 10d-MCF-7-EM (10d - blue bars). The mRNA levels for each gene were normalized to Glyceraldehyde-3-PhosphateDehydrogenase (GAPDH) and expressed as fold of change $\left(2^{-\Delta \Delta C t}\right)$ of the mRNA levels observed in untreated control hADSCs (Ctrl - Grey bar) defined as 1 (mean $\pm \mathrm{SD} ; n=6$ ). Data are expressed as mean $\pm \mathrm{SD}$ referred to the control $(* p \leq 0.05)$.

\subsection{Exhausted MCF- 7 Medium Affects Epigenetic Modulating Genes in hADSCs}

The gene expression of SIRT1 and DNMT1 (Figure 7) was investigated in hADSCs cultured in the presence of an MCF-7 exhausted medium. The expression of these epigenetic genes was significantly upregulated only in ADSCs that had been exposed to 7d-MCF-7EM (7d-green bars), or 10d-MCF-7-EM (10d-blue bars), as compared to control untreated cells (Ctrl-grey bars).
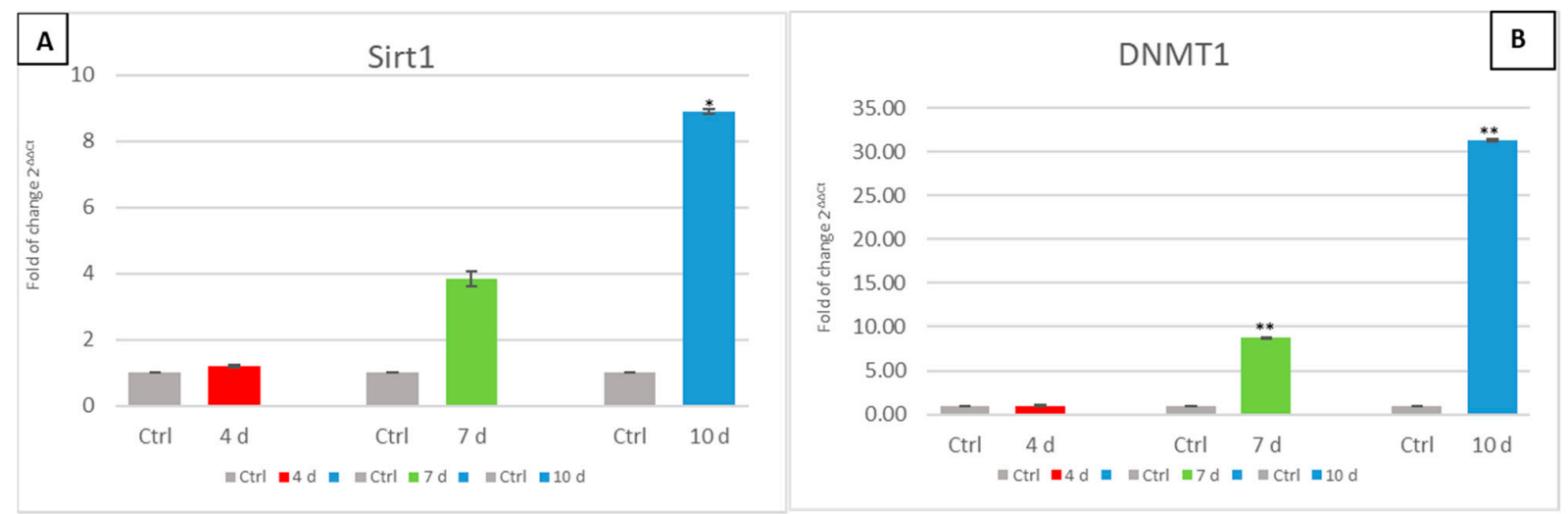

Figure 7. Expression of epigenetic modulating genes. The expression of SIRT1 (Panel (A)) and DNMT1 (Panel (B)) was evaluated in hADSCs cultured in the presence of 4d-MCF-7-EM (4d - red bars), 7d-MCF-7-EM (7d - green bars), or 10d-MCF7-EM (10d - blue bars). The mRNA levels for each gene were normalized to Glyceraldehyde-3-Phosphate-Dehydrogenase (GAPDH) and expressed as fold of change $\left(2^{-\Delta \Delta C t}\right)$ of the mRNA levels observed in untreated control hADSCs (Ctrl - grey bar) defined as 1 (mean $\pm \mathrm{SD} ; n=6)$. Data are expressed as mean $\pm \mathrm{SD}$ referred to the control $\left({ }^{*} p \leq 0.05\right),\left({ }^{* *} p \leq 0.01\right)$. 


\subsection{MCF7-Exhausted Media Induce Autophagy in hADSCS}

Western blotting analysis of autophagosome formation (Figure 8) showed the activation of autophagy in hADSCs exposed to 7d-MCF-7-EM (7d-green bars) or 10d-MCF-7-EM (10d-blue bars), exhibiting higher expression levels of LC3B I and LC3B II and Atg12 proteins, as compared to control untreated cells (Ctrl-grey bars) and to 4d-MCF-7-EM (4d-red bars).
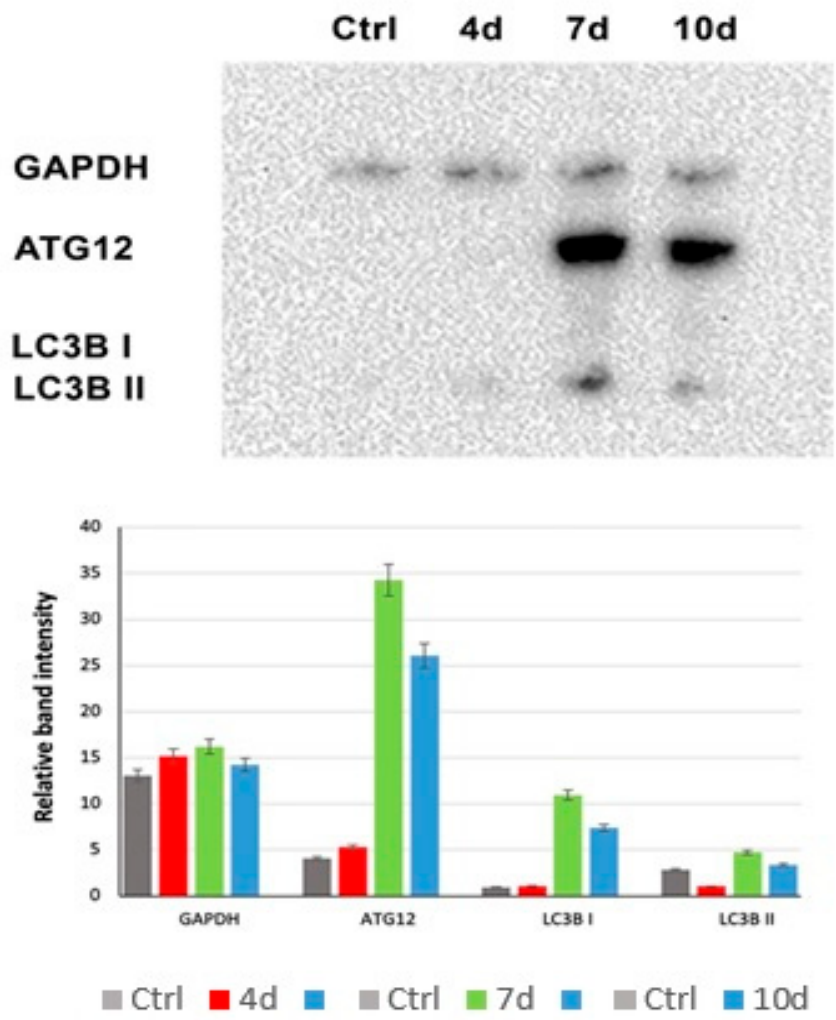

Figure 8. Analysis of autophagosome formation. The protein levels were analyzed on hADSCs cultured with 4d-MCF-7-EM (4d - red bars), 7d-MCF-7-EM (7d - green bars), or 10d-MCF-7-EM (10d blue bars) and control cells (Ctrl - grey bars) after 7 days by Western blot, using an autophagosome marker antibody sampler kit. The sizes of the bands were determined using pre-stained marker proteins. The data presented are representative of different independent experiments.

\subsection{Polyamine Detection}

The polyamine content was evaluated in 4d-MCF-7-EM, 7d-MCF-7-EM, or 10d-MCF7-EM and compared to the control represented by MCF-7 medium alone (referred to as Ctrl). The results in the table show a significant difference in the content of polyamines as compared to the controls $(* * * \leq 0.001)$ for all the analyzed molecules (Table 2 ).

Table 2. Amounts of polyamines (ng/mL) in 4d-MCF-7-EM, 7d-MCF-7-EM, or 10d-MCF-7-EM and MCF-7 fresh medium (Ctrl). The $p$-value is related to the change in concentration of the analytes listed in the table in the medium analyzed.

\begin{tabular}{cccccc}
\hline Polyamines & Ctrl & 4d-MCF-7-EM & 7d-MCF-7-EM & 10d-MCF-7-EM & $p$-Value \\
\hline Putrescine & 0.79 & 0.68 & 0.63 & 0.60 & $0.0005^{* * *}$ \\
Spermidine & 0.98 & 1.054 & 1.27 & 1.35 & $0.0009^{* * *}$ \\
Spermine & 1.29 & 1.22 & 1.09 & 0.86 & $0.001^{* * *}$ \\
Agmantine & 0.8 & 0.65 & 0.60 & 0.61 & $0.0007^{* * *}$ \\
N-acetylputrescine & 0.38 & 0.38 & 0.42 & 0.42 & $0.00003^{* * *}$ \\
N-acetylspermine & 0.411 & 0.420 & 0.510 & 0.515 & $0.0005^{* * *}$ \\
N-acetylspermidine & 0.322 & 0.284 & 0.268 & 0.270 & $0.0002^{* * *}$ \\
\hline
\end{tabular}




\section{Discussion}

Breast reconstruction after mastectomy has become an integral part of breast cancer treatment, giving women the chance to alleviate some of the emotional and aesthetic psychological effects of this disease [40,41]. Adipose tissue represents a valuable source of mesenchymal stem cells [42], easily collectible, able to differentiate toward different cell lineages upon stimulation, therefore representing a suitable tool in regenerative and aesthetic medicine or plastic surgery procedures, such as breast reconstruction after mastectomy [43].

Nevertheless, some issues are still open. In particular, the clear evidence that stem cell behavior and fate are influenced by the cellular microenvironment $[5-7,10,37]$ raises more than a cautionary note on the use of a stem cell source in patients who underwent mastectomy as a part of a breast cancer treatment.

In this study, we evaluated whether a conditioned medium harvested at different time points from breast cancer cells may have been acting on hADSCs to affect their pluripotency, epigenetic gene expression, and autophagy.

The MCF-7 cells represent a model cell line suitable for important research investigations and experiments on breast cancer cells, including anticancer drugs [44]. They release in the medium several factors, such as cytokines, exosomes, and polyamines (Table 2) $[45,46]$ that can induce changes in gene expression (Figures 5-7) and morphology (Figure 2). Other authors previously demonstrated the ability of this medium to induce a transformation in hADSCs toward cancer-associated fibroblasts (CAF) [47,48]. Although transformed, they retain some typical markers of mesenchymal stem cells [49].

Our results show that the expression of stemness genes (OCT4, Sox2, Nanog) was significantly upregulated in hADSCs that had been cultured in the presence of MCF-7-EM and that the exposure effect occurred in a time-dependent fashion.

It is worth considering that the overexpression of these genes could be associated with the initiation of an uncontrolled transformation leading to a malignant phenotype, as it has been documented elsewhere [37].

The analysis of the mRNA levels of p53 and p21 (WAF1/CIP1), involved in cellcycle arrest, revealed the capability of the MCF-7-EM to downregulate the expression of both genes in hADSCs, without altering their viability. Moreover, p53 is associated with the activation of apoptosis through the activation of pro-apoptotic proteins such as BAX [50]. From our results, MCF-7-EM exposure elicited a decrease in the hADSC gene expression of both p53 and BAX, thus indicating the generation of an anti-apoptotic, pro-proliferative state.

Such an indication is further inferred from the observation that SIRT 1 was overexpressed following hADSC exposure to MCF-7-EM. In actual fact, SIRT1 is known to inhibit the expression of p53-regulated genes, inducing p53 deacetylation, thus preventing cellular arrest and apoptosis. Interestingly, not only p53 but even p21p21 (WAF1/CIP1) gene expression was inhibited in MCF-7-EM-exposed hADSCs. p53 activates transcription of p21 (WAF1/CIP1), a cell-cycle inhibitor that promotes both cdk/cyclin inhibition and cell-cycle arrest during the G1/S phase $[24,51,52]$. The currently observed inhibition in p21 gene expression further corroborates the environmental pressure exerted by MCF-7-EM toward a de-regulated proliferative state executed within a risky context of stemness enhancement.

Consonant with this view is the observed increase in DNMT1 transcription in MCF7-EM treated hADSCs. Such overexpression could be related to the maintenance of a methylated state in genes responsible for differentiation, such as RUNX 2 and PPAR $\gamma$, which are conversely hypomethylated in hADSCs undergoing differentiation [53]. This result is particularly interesting within our observed context of MCF-7-EM-induced increase in stemness gene expression since DNMT1 is induced by OCT4 and Nanog by direct binding to its promoter [54].

In order to identify a potential group of molecules capable of orchestrating the molecular changes observed in MCF-7-EM treated hADSCs, we decided to investigate the presence of different polyamines in the MCF-7-EM, considering the ability of these molecules to regulate multifaceted, often intertwined cellular processes. It has been shown that the 
downregulation of some polyamines belonging to the arginine pathway like spermidine causes an arrest in the cell cycle, inhibiting cell proliferation [55].

Compounding the pro-stemness/pro-proliferative, anti-apoptotic environment provided by stem cell exposure to MCF-7-EM, we found that this medium, collected after 4, 7, or 10 days of culturing, expressed significantly different levels of polyamines, as compared with the control medium alone.

The intracellular metabolism of polyamines can be considered a cyclic process, allowing the transformation of a polyamine into another, finely tuning both their accumulation and depletion [56]. The formation of polyamines occurs at the cytoplasmic level, where putrescine, through the action of S-adenosyl-methionine, generates spermidine, which, in turn, by the aid of a transferase, leads to the formation of spermine [57].

Spermine can be converted back into spermidine and spermidine into putrescine via acetylation. These molecules can be released from the cell into the extracellular environment, acting both in a paracrine and autocrine fashion [58,59].

Here, we show higher levels of spermidine and acetylated spermine in MCF-7-EM, as compared to the control medium alone, indicating that these two molecules are rapidly produced by MCF-7. Spermidine plays a key role in cell-cycle progression, as shown by the observation that its rapid depletion caused a total inhibition of protein synthesis and growth arrest [60]. Conversely, both spermidine and acetylated polyamines have been shown to be involved in cell proliferation [61,62].

On these bases, we can hypothesize a role of these molecules, released from MCF-7, as intercellular messengers modulating hADSCs proliferation.

The hypothesis that spermidine produced by MCF-7 could be involved in hADSC transformation contributing to their higher proliferation rate is also in agreement with the downregulation in p53 and p21 (WAF1/CIP1) expression observed here following stem cell exposure to MCF-7-EM since the cell-cycle arrest induced by polyamine depletion is known to be associated with the induction of these cell-cycle inhibitors [55]

Moreover, spermidine can induce autophagy [63]. Autophagy has been shown to be able to maintain stemness, playing a role in stem cell differentiation toward specific lineages, by degrading unwanted organelles and proteins while simultaneously providing building blocks for the neosynthesized biomolecules [64]. Autophagy can be initiated in response to nutrient deprivation and various other stresses [65].

In actual fact, we investigated whether in hADSCs cultured in the presence of MCF-7EM, a different expression of autophagy could be observed. For this purpose, we analyzed the main proteins involved in autophagosome formation, Atg12, LC3B I, and Lc3B II (Figure 8) [66], observing higher levels of all these proteins in hADSCs that had been exposed to 7d-MCF-7-EM and in 10d-MCF-7-EM. The autophagy induced by MCF-7-EM in hADSCs is consonant with the higher proliferation rate observed since autophagy was recently associated with stemness maintenance and inhibition of differentiation [64].

Nevertheless, the levels of spermine, putrescine, and acetyl-spermidine were significantly reduced in MCF-7-EM when compared to the control medium. Additional studies will be required to dissect the effects elicited on hADSC proliferation by the timely changes in the differential expression of these molecules within MCF-7-EM.

\section{Conclusions}

The present observations indicate that factors contained in the exhausted medium of a breast cancer cell line are able to remarkably influence stem cell behavior in vitro by eliciting an increased expression of stemness-related genes and epigenetic genes, together with an increase in cell proliferation, a blockade of differentiation, and maintenance of stem cell potency.

These findings suggest that hADSCs, which are currently transplanted in an increasing number of diseased tissues, may drift to a deregulated and dangerous highly proliferative phenotype when transplanted in a pathological environment in vivo. 
Supplementary Materials: The following are available online at https:/ / www.mdpi.com/article/10 .3390 / cells10071754/s1, Figure S1: Representative chromatograms of analytes in HRMS Orbitrap, Table S1: Calibration curves, Figure S2: Calibration curve and medium release.

Author Contributions: Conceptualization, G.G., F.B., S.C., and M.M.; methodology, G.G., S.C., R.P., E.B., D.C., and E.A.; software, G.G. and S.C.; validation, C.V. and M.M.; formal analysis, G.G., S.C., D.C., and E.A.; investigation, G.G., F.B., and M.M.; resources, M.L.C. and G.C.G.; data curation, G.G. and S.C. writing-original draft preparation, G.G. and S.C.; writing-review and editing, C.V. and M.M.; visualization, C.V. and C.C.; supervision, M.M. All authors have read and agreed to the published version of the manuscript.

Funding: This research was funded by “Fondo di Ateneo per la ricerca 2020 (Margherita Maioli)".

Institutional Review Board Statement: The study was conducted according to the guidelines of the Declaration of Helsinki and approved by the Ethics Committee Review Boards for Human Studies in Sassari n_ETIC 240I/CE 26 July 2016, Ethical committee, ASL Sassari.

Informed Consent Statement: Informed consent was obtained from all subjects involved in the study.

Data Availability Statement: Not applicable.

Conflicts of Interest: The authors declare no conflict of interest.

\section{References}

1. Naderi, N.; Combellack, E.J.; Griffin, M.; Sedaghati, T.; Javed, M.; Findlay, M.W.; Wallace, C.G.; Mosahebi, A.; Butler, P.E.; Seifalian, A.M.; et al. The regenerative role of adipose-derived stem cells (ADSC) in plastic and reconstructive surgery. Int. Wound J. 2017, 14, 112-124. [CrossRef]

2. Wankhade, U.D.; Shen, M.; Kolhe, R.; Fulzele, S. Advances in adipose-derived stem cells isolation, characterization, and application in regenerative tissue engineering. Stem Cells Int. 2016, 2016, 3206807. [CrossRef]

3. Leto Barone, A.A.; Khalifian, S.; Lee, W.P.; Brandacher, G. Immunomodulatory effects of adipose-derived stem cells: Fact or fiction? Biomed Res. Int. 2013, 2013, 383685. [CrossRef] [PubMed]

4. Burrow, K.L.; Hoyland, J.A.; Richardson, S.M. Human adipose-derived stem cells exhibit enhanced proliferative capacity and retain multipotency longer than donor-matched bone marrow mesenchymal stem cells during expansion In Vitro. Stem Cells Int. 2017, 2017, 2541275. [CrossRef]

5. Basoli, V.; Santaniello, S.; Cruciani, S.; Ginesu, G.C.; Cossu, M.L.; Delitala, A.P.; Serra, P.A.; Ventura, C.; Maioli, M. Melatonin and vitamin D interfere with the adipogenic fate of adipose-derived stem cells. Int. J. Mol. Sci. 2017, 18, 981. [CrossRef] [PubMed]

6. Santaniello, S.; Cruciani, S.; Basoli, V.; Balzano, F.; Bellu, E.; Garroni, G.; Ginesu, G.C.; Cossu, M.L.; Facchin, F.; Delitala, A.P.; et al. Melatonin and vitamin D orchestrate adipose derived stem cell fate by modulating epigenetic regulatory genes. Int. J. Med. Sci. 2018, 15, 1631-1639. [CrossRef] [PubMed]

7. Cruciani, S.; Garroni, G.; Balzano, F.; Pala, R.; Bellu, E.; Cossu, M.L.; Ginesu, G.C.; Ventura, C.; Maioli, M. Tuning adipogenic differentiation in ADSCs by metformin and vitamin D: Involvement of miRNAs. Int. J. Mol. Sci. 2020, 21, 6181. [CrossRef]

8. Guilak, F.; Cohen, D.M.; Estes, B.T.; Gimble, J.M.; Liedtke, W.; Chen, C.S. Control of stem cell fate by physical interactions with the extracellular matrix. Cell Stem Cell. 2009, 5, 17-26. [CrossRef]

9. Maioli, M.; Rinaldi, S.; Pigliaru, G.; Santaniello, S.; Basoli, V.; Castagna, A.; Fontani, V.; Ventura, C. REAC technology and hyaluron synthase 2, an interesting network to slow down stem cell senescence. Sci. Rep. 2016, 6, 28682. [CrossRef]

10. Maioli, M.; Santaniello, S.; Montella, A.; Bandiera, P.; Cantoni, S.; Cavallini, C.; Bianchi, F.; Lionetti, V.; Rizzolio, F.; Marchesi, I.; et al. Hyaluronan esters drive Smad gene expression and signaling enhancing cardiogenesis in mouse embryonic and human mesenchymal stem cells. PLoS ONE 2010, 5, e15151. [CrossRef]

11. Chambers, I.; Tomlinson, S.R. The transcriptional foundation of pluripotency. Development 2009, 136, 2311-2322. [CrossRef] [PubMed]

12. Shi, G.; Jin, Y. Role of Oct4 in maintaining and regaining stem cell pluripotency. Stem Cell Res. Ther. 2010, 1, 39. [CrossRef] [PubMed]

13. Han, S.M.; Han, S.H.; Coh, Y.R.; Jang, G.; Ra, J.C.; Kang, S.K.; Lee, H.W.; Youn, H.Y. Enhanced proliferation and differentiation of Oct4- and Sox2-overexpressing human adipose tissue mesenchymal stem cells. Exp. Mol. Med. 2014, 46, e101. [CrossRef] [PubMed]

14. Takahashi, K.; Yamanaka, S. Induction of pluripotent stem cells from mouse embryonic and adult fibroblast cultures by defined factors. Cell 2006, 126, 663-676. [CrossRef] [PubMed]

15. Liu, K.; Lin, B.; Zhao, M.; Yang, X.; Chen, M.; Gao, A.; Liu, F.; Que, J.; Lan, X. The multiple roles for Sox2 in stem cell maintenance and tumorigenesis. Cell. Signal. 2013, 25, 1264-1271. [CrossRef] [PubMed]

16. Sun, A.X.; Liu, C.J.; Sun, Z.Q.; Wei, Z. NANOG: A promising target for digestive malignant tumors. World J. Gastroenterol. 2014, 20, 13071-13078. [CrossRef]

17. Wang, M.L.; Chiou, S.H.; Wu, C.W. Targeting cancer stem cells: emerging role of Nanog transcription factor. Onco. Targets Ther. 2013, 6, 1207-1220. [CrossRef] 
18. Seymour, T.; Twigger, A.-J.; Kakulas, F. Pluripotency genes and their functions in the normal and aberrant breast and brain. Int. J. Mol. Sci. 2015, 16, 27288-27301. [CrossRef]

19. Ling, G.Q.; Chen, D.B.; Wang, B.Q.; Zhang, L.S. Expression of the pluripotency markers Oct3/4, Nanog and Sox2 in human breast cancer cell lines. Oncol. Lett. 2012, 4, 1264-1268. [CrossRef]

20. You, L.; Guo, X.; Huang, Y. Correlation of cancer stem-cell markers OCT4, SOX2, and NANOG with clinicopathological features and prognosis in operative patients with rectal cancer. Yonsei Med. J. 2018, 59, 35-42. [CrossRef]

21. Sharma, S.; Kelly, T.K.; Jones, P.A. Epigenetics in cancer. Carcinogenesis 2010, 31, 27-36. [CrossRef]

22. Montalbán-Loro, R.; Domingo-Muelas, A.; Bizy, A.; Ferrón, S.R. Epigenetic regulation of stemness maintenance in the neurogenic niches. World J. Stem Cells 2015, 7, 700-710. [CrossRef] [PubMed]

23. Zhou, Y.; Kim, J.; Yuan, X.; Braun, T. Epigenetic modifications of stem cells: A paradigm for the control of cardiac progenitor cells. Circ. Res. 2011, 109, 1067-1081. [CrossRef] [PubMed]

24. Rodriguez, R.M.; Fernandez, A.F.; Fraga, M.F. Role of sirtuins in stem cell differentiation. Genes Cancer 2013, 4, 105-111. [CrossRef] [PubMed]

25. Kim, M.; Costello, J. DNA methylation: An epigenetic mark of cellular memory. Exp. Mol. Med. 2017, 49, e322. [CrossRef] [PubMed]

26. Pathania, R.; Ramachandran, S.; Elangovan, S.; Padia, R.; Yang, P.; Cinghu, S.; Veeranan-Karmegam, R.; Arjunan, P.; GnanaPrakasam, J.P.; Sadanand, F.; et al. DNMT1 is essential for mammary and cancer stem cell maintenance and tumorigenesis. Nat. Commun. 2015, 6, 6910. [CrossRef]

27. Jin, X.; Wei, Y.; Xu, F.; Zhao, M.; Dai, K.; Shen, R.; Yang, S.; Zhang, N. SIRT1 promotes formation of breast cancer through modulating Akt activity. J. Cancer 2018, 9, 2012-2023. [CrossRef] [PubMed]

28. O'Halloran, N.; Khan, S.; Gilligan, K.; Dwyer, R.; Kerin, M.; Lowery, A. Oncological risk in autologous stem cell donation for novel tissue-engineering approaches to postmastectomy breast regeneration. breast cancer (Auckl). Breast Cancer Basic Clin. Res. 2019, 13, 1178223419864896. [CrossRef]

29. Sistigu, A.; Musella, M.; Galassi, C.; Vitale, I.; De Maria, R. Tuning cancer fate: Tumor microenvironment's role in cancer stem cell quiescence and reawakening. Front. Immunol. 2020, 11, 2166. [CrossRef]

30. Wang, M.; Zhao, J.; Zhang, L.; Wei, F.; Lian, Y.; Wu, Y.; Gong, Z.; Zhang, S.; Zhou, J.; Cao, K.; et al. Role of tumor microenvironment in tumorigenesis. J. Cancer 2017, 8, 761-773. [CrossRef]

31. Cozzo, A.J.; Fuller, A.M.; Makowski, L. Contribution of adipose tissue to development of cancer. Compr. Physiol. 2017, 8, 237-282. [CrossRef]

32. Dominiak, A.; Chełstowska, B.; Olejarz, W.; Nowicka, G. Communication in the cancer microenvironment as a target for therapeutic interventions. Cancers 2020, 12, 1232. [CrossRef] [PubMed]

33. Wallace, H.M.; Huang, Y.; Marton, L.J.; Woster, P.M.; Casero, R.A. Polyamine analogues targeting epigenetic gene regulation. Essays Biochem. 2009, 46, 95-110. [CrossRef]

34. Pegg, A.E. Functions of polyamines in mammals. J. Biol. Chem. 2016, 291, 14904-14912. [CrossRef] [PubMed]

35. Borzì, R.M.; Guidotti, S.; Minguzzi, M.; Facchini, A.; Platano, D.; Trisolino, G.; Filardo, G.; Cetrullo, S.; D'Adamo, S.; Stefanelli, C.; et al. Polyamine delivery as a tool to modulate stem cell differentiation in skeletal tissue engineering. Amino Acids 2014, 46, 717-728. [CrossRef] [PubMed]

36. Coradduzza, D.; Azara, E.; Medici, S.; Arru, C.; Solinas, T.; Madonia, M.; Zinellu, A.; Carru, C. A preliminary study procedure for detection of polyamines in plasma samples as a potential diagnostic tool in prostate cancer. J. Chromatogr. B. 2021, 1162, 122468. [CrossRef]

37. Balzano, F.; Garroni, G.; Cruciani, S.; Bellu, E.; Dei Giudici, S.; Oggiano, A.; Capobianco, G.; Dessole, S.; Ventura, C.; Maioli, M. Behavioral changes in stem-cell potency by HepG2-exhausted medium. Cells 2020, 9, 1890. [CrossRef] [PubMed]

38. Glick, D.; Barth, S.; Macleod, K.F. Autophagy: Cellular and molecular mechanisms. J. Pathol. 2010, 221, 3-12. [CrossRef]

39. Chen, N.; Debnath, J. Autophagy and tumorigenesis. FEBS Lett. 2010, 584, 1427-1435. [CrossRef]

40. Connors, S.K.; Goodman, M.S.; Myckatyn, T.; Margenthaler, J.; Gehlert, S. Breast reconstruction after mastectomy at a comprehensive cancer center. SpringerPlus 2016, 5, 955. [CrossRef]

41. Qin, Q.; Tan, Q.; Lian, B.; Mo, Q.; Huang, Z.; Wei, C. Postoperative outcomes of breast reconstruction after mastectomy: A retrospective study. Medicine 2018, 97, e9766. [CrossRef] [PubMed]

42. Mehrabani, D.; Mehrabani, G.; Zare, S.; Manafi, A. Adipose-derived stem cells (ADSC) and aesthetic surgery: A mini review. World J. Plast. Surg. 2013, 2, 65-70. [PubMed]

43. Zuk, P.A.; Zhu, M.; Ashjian, P.; De Ugarte, D.A.; Huang, J.I.; Mizuno, H.; Alfonso, Z.C.; Fraser, J.K.; Benhaim, P.; Hedrick, M.H. Human adipose tissue is a source of multipotent stem cells. Mol. Biol. Cell 2002, 13, 4279-4295. [CrossRef]

44. Comşa, Ş.; Cîmpean, A.M.; Raica, M. The story of MCF-7 breast cancer cell line: 40 years of experience in research. Anticancer Res. 2015, 35, 3147-3154. [PubMed]

45. Chen, K.; Satlof, L.; Stoffels, G.; Kothapalli, U.; Ziluck, N.; Lema, M.; Poretsky, L.; Avtanski, D. Cytokine secretion in breast cancer cells-MILLIPLEX assay data. Data Brief 2019, 28, 104798. [CrossRef]

46. Tan, A.A.; Phang, W.M.; Gopinath, S.C.; Hashim, O.H.; Kiew, L.V.; Chen, Y. Revealing glycoproteins in the secretome of MCF-7 human breast cancer cells. BioMed Res. Int. 2015, 2015, 453289. [CrossRef] 
47. Visweswaran, M.; Keane, K.N.; Arfuso, F.; Dilley, R.J.; Newsholme, P.; Dharmarajan, A. The influence of breast tumour-derived factors and Wnt antagonism on the transformation of adipose-derived mesenchymal stem cells into tumour-associated fibroblasts. Cancer Microenviron. 2018, 11, 71-84. [CrossRef]

48. Cho, J.A.; Park, H.; Lim, E.H.; Lee, K.W. Exosomes from breast cancer cells can convert adipose tissue-derived mesenchymal stem cells into myofibroblast-like cells. Int. J. Oncol. 2012, 40, 130-138. [CrossRef]

49. Paunescu, V.; Bojin, F.M.; Tatu, C.A.; Gavriliuc, O.I.; Rosca, A.; Gruia, A.T.; Tanasie, G.; Bunu, C.; Crisnic, D.; Gherghiceanu, M.; et al. Tumour-associated fibroblasts and mesenchymal stem cells: More similarities than differences. J. Cell. Mol. Med. 2011, 15, 635-646. [CrossRef]

50. Whitaker, R.H.; Placzek, W.J. Regulating the BCL2 family to improve sensitivity to microtubule targeting agents. Cells 2019, 8, 346. [CrossRef]

51. Zhou, N.; Lin, X.; Dong, W.; Huang, W.; Jiang, W.; Lin, L.; Qiu, Q.; Zhang, X.; Shen, J.; Song, Z.; et al. SIRT1 alleviates senescence of degenerative human intervertebral disc cartilage endo-plate cells via the p53/p21 pathway. Sci. Rep. 2016, 6, 22628. [CrossRef]

52. Fujino, T.; Yokokawa, R.; Oshima, T.; Hayakawa, M. SIRT1 knockdown up-regulates p53 and p21/Cip1 expression in renal adenocarcinoma cells but not in normal renal-derived cells in a deacetylase-independent manner. J. Toxicol. Sci. 2018, 43, 711-715. [CrossRef] [PubMed]

53. Chen, R.; Ren, L.; Cai, Q.; Zou, Y.; Fu, Q.; Ma, Y. The role of epigenetic modifications in the osteogenic differentiation of adipose-derived stem cells. Connect Tissue Res. 2019, 60, 507-520. [CrossRef] [PubMed]

54. Tsai, C.C.; Su, P.F.; Huang, Y.F.; Yew, T.L.; Hung, S.C. Oct4 and Nanog directly regulate Dnmt1 to maintain self-renewal and undifferentiated state in mesenchymal stem cells. Mol. Cell 2012, 47, 169-182. [CrossRef]

55. Ray, R.M.; Zimmerman, B.J.; McCormack, S.A.; Patel, T.B.; Johnson, L.R. Polyamine depletion arrests cell cycle and induces inhibitors p21(Waf1/Cip1), p27(Kip1), and p53 in IEC-6 cells. Am. J. Physiol. 1999, 276, C684-C691. [CrossRef] [PubMed]

56. Seiler, N. Functions of polyamine acetylation. Can. J. Physiol. Pharmacol. 1987, 65, 2024-2035. [CrossRef] [PubMed]

57. Pegg, A.E. Mammalian polyamine metabolism and function. IUBMB Life 2009, 61, 880-894. [CrossRef]

58. Bekebrede, A.F.; Keijer, J.; Gerrits, W.J.J.; Boer, V.C.J.d. The molecular and physiological effects of protein-derived polyamines in the intestine. Nutrients 2020, 12, 197. [CrossRef]

59. Sandusky-Beltran, L.A.; Kovalenko, A.; Ma, C.; Calahatian, J.I.T.; Placides, D.S.; Watler, M.D.; Hunt, J.B.; Darling, A.L.; Baker, J.D.; Blair, L.J.; et al. Spermidine/spermine-N1-acetyltransferase ablation impacts tauopathy-induced polyamine stress response. Alzheimers Res. Ther. 2019, 11, 58. [CrossRef]

60. Mandal, S.; Mandal, A.; Johansson, H.E.; Orjalo, A.V.; Park, M.H. Depletion of cellular polyamines, spermidine and spermine, causes a total arrest in translation and growth in mammalian cells. Proc. Natl. Acad. Sci. USA 2013, 110, 2169-2174. [CrossRef]

61. Desiderio, M.A.; Bardella, L. Polyamine acetylations in normal and neoplastic growth processes. Amino Acids 1995, 8, 59-68. [CrossRef]

62. Park, M.H.; Igarashi, K. Polyamines and their metabolites as diagnostic markers of human diseases. Biomol. Ther. 2013, 21, 1-9. [CrossRef]

63. Eisenberg, T.; Knauer, H.; Schauer, A.; Büttner, S.; Ruckenstuhl, C.; Carmona-Gutierrez, D.; Ring, J.; Schroeder, S.; Magnes, C.; Antonacci, L.; et al. Induction of autophagy by spermidine promotes longevity. Nat. Cell. Biol. 2009, 11, 1305-1314. [CrossRef] [PubMed]

64. Chen, X.; He, Y.; Lu, F. Autophagy in stem cell biology: A Perspective on stem cell self-renewal and differentiation. Stem Cells Int. 2018, 2018, 9131397. [CrossRef] [PubMed]

65. Chang, N.C. Autophagy and stem cells: Self-eating for self-renewal. Front. Cell Dev. Biol. 2020, 8, 138. [CrossRef] [PubMed]

66. Mai, S.; Muster, B.; Bereiter-Hahn, J.; Jendrach, M. Autophagy proteins LC3B, ATG5 and ATG12 participate in quality control after mitochondrial damage and influence lifespan. Autophagy 2012, 8, 47-62. [CrossRef] 